\title{
Análise da durabilidade do concreto de alto desempenho com adição de cinza de casca de arroz e borracha de pneu
}

\author{
Analysis of durability of high-performance concrete with \\ addition of rice husk ash and rubber tire
}

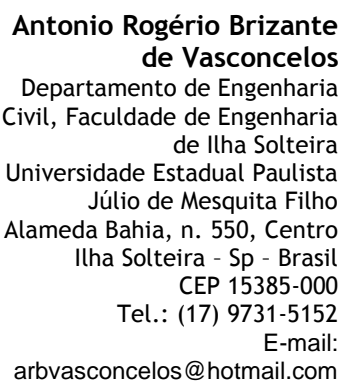

Jorge Luís Akasaki Departamento de Engenharia Civil, Faculdade de Engenharia de llha Solteira Universidade Estadual Paulista Júlio de Mesquita Filho

Tel.: (18) 3743-1213 E-mail:

akasaki@dec.feis.unesp.br

Recebido em 18/05/09

Aceito em 16/02/10

\section{Antonio Rogério Brizante de Vasconcelos Jorge Luís Akasaki}

\section{Resumo}

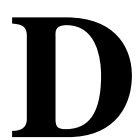

esde a década de 70 o Brasil vem apresentando uma crescente degradação nas suas estruturas de concreto armado. Por esta razão, inúmeras pesquisas relacionadas à durabilidade destas estruturas têm sido realizadas, visando a contribuir com a qualidade e com a redução dos custos com manutenção e reparos. Este trabalho avaliou o comportamento da durabilidade do concreto de alto desempenho com adições, substituindo parte de cimento e agregados presentes no concreto pela cinza da casca de arroz e borracha de pneu respectivamente. Foram realizados ensaios de durabilidade submetendo o concreto a diversos processos de degradação, como a ação da água, temperatura, sais e solução ácida. $\mathrm{O}$ estudo indicou que a durabilidade não foi comprometida com adição de sílica ativa ou cinza da casca de arroz, com a adição de borracha de pneu. De fato, a borracha mostrou-se muito eficaz no combate a ação de agentes químicos, a altas temperaturas e à entrada de água. Com a cinza da casca de arroz, apesar do maior diâmetro de suas partículas, conseguiu-se resultados similares em relação à sílica ativa.

Palavras-chave: Concreto de alto desempenho. Durabilidade. Borracha de pneu. Cinza da casca de arroz.

\section{Abstract}

Since the Seventies, there has been a growing degradation of concrete structures in Brazil. For that reason, much research has been made on the durability of those structures, aiming at contributing towards quality improvement and reduction of maintenance and repair costs. This study evaluates the behavior of the durability of high-performance concrete with additions, replacing part of the cement and aggregates with rice husk ash and tire rubber, respectively. Durability tests were carried out in which concrete was subjected to several degradation processes, such as the action of water, temperature, salts and acid solution. The results indicated that the addition of active silica or rice husk ash, both with tire rubber did not worsen the durability of concrete. In fact, rubber proved to be very effective in preventing the action of chemical agents, high temperatures and the penetration of water. Rice husk ash, despite the larger diameter of particles, had similar results to that of the active silica.

Keywords: High-Performance concrete. Durability. Tire rubber. Rice husk ash. 


\section{Introdução}

O país possui uma das maiores safras mundiais de arroz. Segundo Arroz Brasileiro (2008), a safra 2007/2008 teve mais de 11 milhões de toneladas de grãos em casca produzidos, sendo a cinza da casca de arroz correspondente a $4 \%$ do peso do arroz em casca.

O Brasil encontra um grande desafio para conseguir dar finalidade adequada aos pneus em seu território. São mais de 40 milhões produzidos a cada ano e quase a metade acaba sendo descartada sem controle (AMBIENTE BRASIL, 2007).

A incorporação de resíduos industriais ao concreto, como a cinza da casca de arroz (CCA), pode ser uma importante forma de conduzi-los a uma finalidade nobre e ambientalmente correta, tornando-se uma das soluções para o aproveitamento de subprodutos poluentes (PRUDÊNCIO JUNIOR; SANTOS; DAFICO, 2003).

Com vistas à durabilidade, alguns resíduos, quando adicionados às pastas, às argamassas e aos concretos, podem ser benéficos, enaltecendo propriedades do material, além de tornar resíduos fontes de matéria-prima para a construção civil.

Segundo Isaia (2005), as obras construídas no século $\mathrm{XX}$ tiveram queda na durabilidade, pois se buscou aumentar a velocidade de construção delas. Para isso, usaram-se cimentos com maior resistência inicial e maior quantidade de aglomerante por metro cúbico de concreto produzido, o que aumentou o calor de hidratação, que, por consequência, gerou fissuração e deixou as estruturas sujeitas à ação dos agentes agressores.

A grande causa de patologias no concreto está relacionada à água, já que esta é solvente universal, sendo responsável, na maioria das vezes, por trocas químicas e físicas, produzindo uma ação degenerativa a partir da dissolução dos compósitos do concreto.

O tamanho dos poros e a conexão entre eles têm grande importância na durabilidade, pois, em termos gerais, a resistência do concreto às influências químicas e físicas é significativamente reduzida com o aumento dos poros capilares (FERREIRA, 2006).

Segundo Mehta e Monteiro (1994), a durabilidade pode ser expressa como a capacidade de uma estrutura em manter um desempenho mínimo em determinado período, sob a influência de agentes agressivos. Para tanto, é necessário saber o tipo, a finalidade e os agentes agressores da estrutura, para analisar seu comportamento ao longo do tempo.
Segundo Zhang, Lastra e Malhotra (1996), a incorporação da CCA para uso em concreto consegue reduzir a porosidade deste e a quantidade de $\mathrm{Ca}(\mathrm{OH})_{2}$ na interface da zona de transição, reduzindo a largura entre o agregado e a pasta de cimento. Entretanto, a porosidade da CCA na zona de transição ainda é maior em relação à sílica ativa (SA).

Os resultados de Hernández e Barluenga (2003) mostraram que a adição de $3 \%$ de borracha no concreto, em relação ao volume, obteve melhor resultado que as demais porcentagens dessa adição no ensaio de resistência à compressão. Também para avaliação do efeito da alta temperatura no concreto, a adição de $3 \%$ de borracha reduziu a fissuração e o destacamento superficial.

Para Medeiros (2005), a presença de microfissuras na pasta endurecida, em conjunto com as ações de absorção e difusão do concreto, permite a entrada de agentes agressores que geram reações com $\mathrm{Ca}(\mathrm{OH})_{2}$, que é solúvel na presença de água, produzindo gesso $\left(\mathrm{CaCO}_{3}\right)$, e com $\mathrm{SO}_{3}, \mathrm{CO}_{2}$ ou $\mathrm{Cl}^{-}$, produzindo $\mathrm{CaCl}_{2}$.

Segundo Chan e Wu (2000), a análise da durabilidade de concretos com substituição de cimento por resíduos foi realizada por meio da comparação dos resultados de absorção, de permeabilidade à água, de resistência à compressão e de consistência. Seus estudos indicaram que os concretos podem ser duráveis mesmo com a substituição de parte da massa de cimento por resíduos. $\mathrm{O}$ aumento da resistência à compressão teve relação direta com o decréscimo da absorção de água e da permeabilidade. Além disso, resíduos podem ser utilizados como superplastificantes, para resolver o problema do consumo de água por materiais mais finos, para manter a consistência do concreto.

Santos et al. (2006) verificou que o concreto com baixa permeabilidade e alta resistência à compressão teve comportamento satisfatório sob a ação de ácidos, no local de aplicação de seu estudo de caso. $\mathrm{O}$ pH da estrutura apresentou apenas alteração numa faixa próxima à superfície, sem ocasionar queda de resistência à compressão significativa e também sem comprometer a durabilidade da estrutura de curto a médio prazo.

Segundo Akasaki et al. (2008), o efeito da adição de $5 \%$ e $10 \%$ de CCA no concreto ocasionou a queda na profundidade de penetração de água, embora seus resultados de absorção de água mostrassem que com apenas $10 \%$ de CCA houve queda na absorção de água por imersão. Com referência ao ensaio de abrasão, a adição de CCA 
mostrou, para todos os teores de substituição, resultados melhores que o concreto-referência.

Sensale e Dal Molin (2001) relataram que o quesito durabilidade, avaliado pelos ensaios de absorção capilar e permeabilidade, mostrou que a cinza da casca de arroz contribui para a queda da permeabilidade e da capilaridade em relação ao traço controle.

Segundo Andrade et al. (2003), a degradação do concreto por origem ácida não mantém uma relação direta com a resistência mecânica, mas a relação água/cimento $(\mathrm{a} / \mathrm{c})$ e o processo de cura são fatores de influência contra $\mathrm{o}$ ataque de agentes agressores no concreto. Já as adições minerais podem ser benéficas aos ataques químicos devido à melhor fixação do $\mathrm{Ca}(\mathrm{OH})_{2}$, produto mais vulnerável na pasta de cimento.

Para Vieira et al. (2008), tanto a diminuição do fator água/aglomerante quanto a adição de sílica ativa melhoram consideravelmente a resistência do concreto ante a ação de agentes agressores. As maiores perdas de massa ocorreram para os CPs imersos em solução de ácido lático.

O efeito da adição da sílica ativa também foi verificado por Dal Molin et al. (1996). A maior perda de massa para o ensaio de resistência ao ataque químico com ácido lático foi para a maior relação a/c e para o traço sem adição de sílica ativa.

Segundo Silva e Libório (2004), não houve muita modificação na absorção por capilaridade comparando-se os resultados de 7 e 28 dias de ensaio, mas a introdução de sílica de ferro-silício apresentou queda de $48 \%$ em relação ao traço controle, enquanto a sílica da casca de arroz diminuiu em $12 \%$ a absorção capilar. Ainda segundo os autores, quanto menor o diâmetro dos poros capilares, maior a pressão e, assim, maior a profundidade de penetração da água no concreto. Portanto, quanto maior o diâmetro dos poros capilares, menor a profundidade do concreto atingida pela água absorvida.

\section{Desenvolvimento do trabalho}

A avaliação da durabilidade foi realizada pelas propriedades do concreto de alto desempenho, que, de uma maneira geral, podem qualificar sua potencialidade, tendo como traço-referência um concreto produzido com sílica ativa, uma pozolana de uso comercial de $2,18 \mathrm{~g} / \mathrm{cm}^{3}$ e cimento CPV ARI PLUS de $3,03 \mathrm{~g} / \mathrm{cm}^{3}$.

A primeira etapa do trabalho consistiu em definir tanto os materiais de estudo quanto a forma de análise a ser empregada na pesquisa, para realizar os ensaios de caracterização química e física.

Os resíduos de borracha de pneu foram peneirados em um agitador mecânico e separados de impurezas como fios de nylon e aço. Na Figura 1 apresentam-se amostras da borracha de pneu após passar pelo processo de peneiramento (Tabela 1).

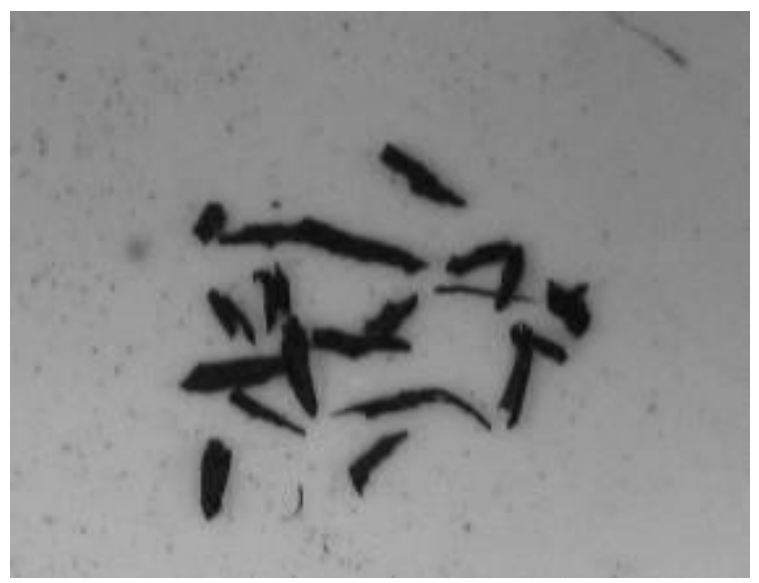

Figura 1 - Fragmentos de borracha de pneu

\begin{tabular}{c|c|c|c}
\hline \multicolumn{2}{c|}{ Peneiras normais e auxiliares } & \multicolumn{2}{c}{ Resíduo de borracha de pneu } \\
\hline Denominação & Abertura $(\mathbf{m m})$ & \% Retida & Denominação \\
\hline $1 / 4 "$ & 6,3 & 1,9 & Borracha muito grossa \\
\hline $\mathrm{N}^{\mathbf{0}} 8$ & 2,38 & 45,9 & Borracha grossa \\
\hline $\mathrm{N}^{\mathbf{o}} 16$ & 1,19 & 27,2 & Borracha média \\
\hline Fundo & 0,075 & 25,0 & Borracha fina \\
\hline
\end{tabular}


Tabela 1 - Classificação granulométrica do resíduo de borracha de pneu

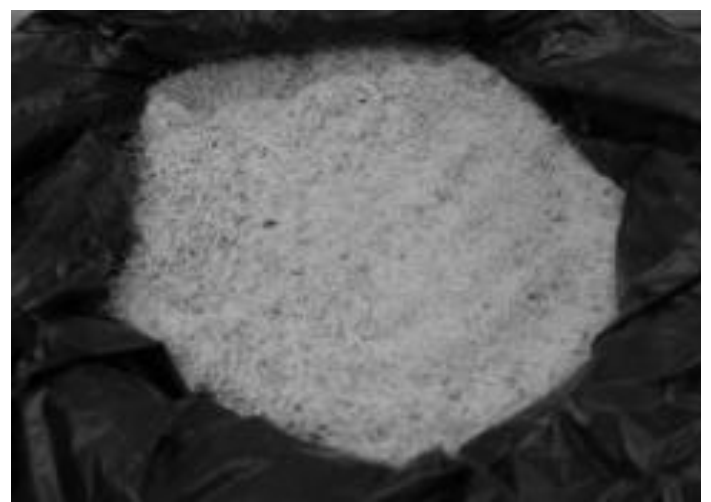

Figura 2 - Casca de arroz após a queima

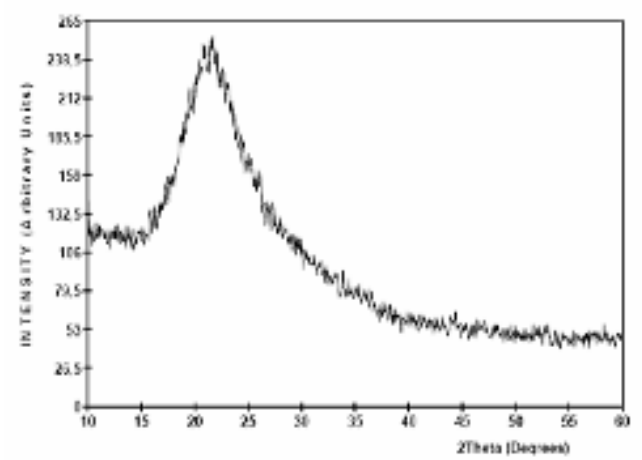

Figura 3 - Difratograma de raios $\mathrm{X}$ da CCA

Embora a CCA usada no trabalho tenha provindo de queima sem controle de temperatura, a cinza era de alta qualidade, clara e amorfa. O tempo de moagem da CCA foi de $40 \mathrm{~min}$ em moinho de bolas, tendo resultado uma cinza com $2,15 \mathrm{~g} / \mathrm{cm}^{3} \mathrm{e}$ diâmetro médio de $12,50 \mu \mathrm{m}$.

A Figura 2 mostra a casca de arroz após a queima, e a Figura 3 mostra o difratograma da CCA, cujo desvio da linha de base entre 15 e 17 graus demonstra sua característica amorfa.

Após os resultados da caracterização, iniciou-se a confecção experimental do traço de concreto de alto desempenho, com quatro tipos diferentes de dosagens:

(a) CAD referência, com adição de sílica ativa;

(b) CAD somente com CCA;

(c) CAD com adiçõos de CCA e resíduo de borracha de pneu; e

(d) CAD com resíduo de borracha e sílica ativa.

Os traços de concreto de alto desempenho realizados neste trabalho partiram dos estudos de Barbosa (2006), em que foram propostas as quantidades ótimas de aditivo, de granulometria e de substituição de cimento.
Barbosa (2006) produziu os traços do CAD baseando-se no método proposto por Aitcin (2000), mediante resultados empíricos e a seleção das características requeridas para o traço, como relação a/c, resistência à compressão, teor de água, teor de agregado graúdo e teor de ar incorporado.

Com o intuito de melhorar as condições de aplicação dos concretos, optou-se pela realização de um ajuste no traço, com o auxílio dos técnicos do Laboratório CESP de Engenharia Civil de Ilha Solteira, melhorando a consistência do concreto com o aumento da relação a/c de 0,30 para 0,355 e da quantidade de argamassa no traço. $O$ ajuste realizado reduziu a quantidade de aditivo de $1,50 \%$ para $0,40 \%$, mantendo o abatimento do tronco de cone em torno de $20 \pm 2 \mathrm{~cm}$. Obteve-se mais facilidade na aplicação do concreto, além de dar mais estabilidade ao concreto, diminuindo o risco de segregação.

A Tabela 2 mostra as especificações dos traços realizados neste trabalho.

$\mathrm{Na}$ escolha dos ensaios optou-se basicamente por aqueles que dependem da água para sua realização, por ser ela um grande mecanismo de propagação das intempéries que agem sobre o concreto. 


\begin{tabular}{c|r|r|r|r}
\hline Material & $\begin{array}{c}\text { Controle }(5 \% \\
\text { SA) }\end{array}$ & 5\% CCA & $\begin{array}{c}\text { SA } \\
\text { Borracha }\end{array}$ & $\begin{array}{c}\text { CCA } \\
\text { Borracha }\end{array}$ \\
\hline Cimento $\left(\mathrm{kg} / \mathrm{m}^{3}\right)$ & 428,800 & 428,800 & 428,800 & 428,800 \\
\hline Sílica ativa $\left(\mathrm{kg} / \mathrm{m}^{3}\right)$ & 16,000 & - & 16,000 & - \\
\hline CCA $\left(\mathrm{kg} / \mathrm{m}^{3}\right)$ & - & 15,720 & - & 15,720 \\
\hline Agregado graúdo $\left(\mathrm{kg} / \mathrm{m}^{3}\right)$ & $1.081,100$ & $1.081,100$ & $1.081,100$ & $1.081,100$ \\
\hline Agregado miúdo $\left(\mathrm{kg} / \mathrm{m}^{3}\right)$ & 812,600 & 812,600 & 733,100 & 733,100 \\
\hline Borracha de pneu $\left(\mathrm{kg} / \mathrm{m}^{3}\right)$ & - & - & 34,500 & 34,500 \\
\hline Água $\left(\mathrm{l} / \mathrm{m}^{3}\right)$ & 170,900 & 170,900 & 170,800 & 170,800 \\
\hline Aditivo $\left(\mathrm{kg} / \mathrm{m}^{3}\right)$ & 2,257 & 2,257 & 2,257 & 2,257 \\
\hline Água/Aglomerante $(\mathrm{a} / \mathrm{agl})$. & 0,355 & 0,355 & 0,355 & 0,355 \\
\hline
\end{tabular}

Tabela 2 - Traços definitivos

A grande absorção de água numa estrutura pode implicar maior facilidade de transporte de íons, ocasionando o processo chamado de lixiviação, que retira partículas do interior do concreto, nas inúmeras vezes em que a água entra e sai da estrutura. $\mathrm{O}$ processo ainda pode ser agravado se esses íons chegarem às armaduras, dando início a processos corrosivos.

Para a execução do ensaio de absorção de água e porosidade, aplicaram-se os procedimentos das normas NBR 9778 (ABNT, 2005) e NBR 9779 (ABNT, 1995), com a moldagem de 3 corpos de prova (CPs) com dimensões de $10 \times 20 \mathrm{~cm}$, nas idades de 7 e 28 dias.

A avaliação da permeabilidade do concreto foi realizada pelo método descrito pela norma NBR 10787 (ABNT, 1994).

Realizou-se o ensaio com 2 CPs com dimensão de $25 \times 25 \times 12,5 \mathrm{~cm}$, consistindo na aplicação de 0,7 MPa de pressão de água no ensaio. Após esse procedimento, cada CP foi levado até a prensa hidráulica para rompimento, para separá-lo em duas partes iguais, no sentido em que foi exercida a pressão da água. Anotaram-se, então, as profundidades de penetração da água em milímetros, ao longo de uma faixa central de 100 $\mathrm{mm}$.

O efeito das altas temperaturas e da variação brusca de clima foi reproduzido em um ensaio de ciclagem água/estufa, de forma análoga ao ensaio para agregados, seguindo a norma NBR 12696 (ABNT, 1992). O período de ensaio foi de 4 meses, com 120 ciclos alternados de permanência na câmara úmida e secagem em estufa. Os CPs, com a dimensão de $10 \times 20 \mathrm{~cm}$, foram distribuídos em grupos de 3 para cada traço. Após o período de cura em câmara úmida, foram deixados em local com umidade ambiente, para a realização da pesagem inicial, e imersos em água por $14 \mathrm{~h}$. Depois, foram secos em estufa por $8 \mathrm{~h}$ e deixados para resfriamento em temperatura ambiente por 1 h. $\mathrm{Na}$ sequência, os $\mathrm{CPs}$ foram pesados novamente, concluindo-se um ciclo.

O ensaio de resistência ao ataque químico sob a ação de ácidos foi realizado pelas avaliações dos resultados de perda de massa, aspecto visual e queda de resistência mecânica, quando os CPs foram submetidos a ciclos de imersão e secagem em solução contendo ácido lático, um dos ácidos orgânicos mais agressivos ao concreto e comumente utilizado em indústrias de produtos lácteos.

Esses CPs eram cilíndricos, sendo 6 deles para cada traço, de dimensão de $10 \times 20 \mathrm{~cm}$, e foram inseridos em soluções contendo ácido lático, em uma concentração igual a $14 \%$, seguindo os procedimentos já adotados por outros autores.

O ácido lático é encontrado em indústrias de laticínio, a partir da fermentação da lactose, ou em indústrias de produtos químicos. A ação deletéria desse agente agressivo sobre o concreto consiste na dissolução do $\mathrm{Ca}(\mathrm{OH})_{2}$ a partir da superfície do concreto, levando à lixiviação desse produto de hidratação (BICZÓK $1964^{1}$ apud DAL MOLIN et al., 1996).

$\mathrm{O}$ modelo de ensaio teve como base as pesquisas de Andrade et al. (2003) e Dal Molin et al. (1996). Ao término do período de cura, 28 dias, os espécimes foram retirados e secos ao ar por $24 \mathrm{~h} \mathrm{e}$, logo após, pesados. Após a pesagem, foram

${ }^{1}$ BICZÓK, I. Concrete Corrosion and Concrete Protection. Budapeste: Akadémiai Kiado, 1964. 
imersos em ácido por 5 dias. Na sequência foram retirados do recipiente contendo ácido e lavados, para retirar os resíduos de concreto, além dos sais solúveis resultantes das trocas químicas entre o cimento e a solução ácida depositados em sua superfície, deixando-os secar ao ar livre por 6 dias. Passado esse período, concluiu-se um ciclo com 11 dias e iniciou-se outro. Mediante 2 ciclos desse ensaio já se observou claramente o comportamento das adições em estudo.

O ensaio da frente de penetração de cloretos foi realizado pelo método colorimétrico de aspersão de nitrato de prata, observado após 4 ciclos de molhagem e secagem, iniciados após 28 dias de cura. A exposição a esse tipo de ataque em ambiente marinho seria por volta de $3,5 \%$ de $\mathrm{NaCl}$ de concentração, mas, segundo os ensaios realizados por Silva (2006), a observação da frente de penetração nesse período do ensaio seria muito pequena. Assim, a concentração utilizada foi de $10 \%$ de $\mathrm{NaCl}$. Após o período de cura, os CPs foram deixados em local com umidade ambiente por 4 dias. $\mathrm{Na}$ sequência foram imersos, com metade da altura, na solução de $0,1 \mathrm{M}$ de $\mathrm{NaCl}$ por 3 dias. Após esse período, os CPs passaram por secagem por 4 dias, completando-se um ciclo.

A perda de material por deterioração da estrutura por desgaste superficial foi expressa pelo valor percentual de perda de massa consequente do desgaste exposto pelo ensaio de abrasão/erosão realizado com uma carga abrasiva de esferas de aço agitadas num compartimento cilíndrico e em contato com a superfície do concreto, seguindo o método Corps of Engineers, apresentado no texto Abrasion-Erosion Resistence of Concrete Technical Report C-78-4, utilizado pelo Laboratório CESP de Engenharia Civil, com a confecção de $1 \mathrm{CP}$ por traço para 7 dias e de 1 para 28 dias.

\section{Resultados, análise e discussão}

As Tabelas 3, 4 e 5 mostram os ensaios preliminares de caracterização dos materiais areia, brita e borracha respectivamente.

A influência das adições na consistência desse concreto foi mínima. A pequena diferença entre os tipos de grãos da sílica ativa, que são esféricos, e cinza da casca de arroz, que possui partículas porosas e o formato alongado da fibra de borracha, pode ter ocasionado essa variação quase insignificante, como observado na Tabela 6. O ensaio seguiu as recomendações da NBR NM 67:1998.

\begin{tabular}{|c|c|c|c|c|c|c|c|c|c|c|c|c|}
\hline Peneiras & \multicolumn{12}{|c|}{$\%$ Retida acumulada } \\
\hline$(\mathrm{mm})$ & 0,075 & 0,150 & 0,300 & 0,600 & 1,18 & 2,36 & 4,75 & 6,3 & 9,5 & 12,5 & 19 & 25 \\
\hline Areia & 100,0 & 97,4 & 84,7 & 47,8 & 27,0 & 8,9 & 0,5 & 0,2 & 0,0 & 0,0 & 0,0 & 0,0 \\
\hline \multirow{3}{*}{$\begin{array}{c}\Phi \\
\text { Máx. } \\
(\mathrm{mm})\end{array}$} & \multirow{3}{*}{$\begin{array}{c}\text { Modulo } \\
\text { de } \\
\text { Finura }\end{array}$} & \multicolumn{4}{|c|}{ Massa específica } & \multicolumn{7}{|c|}{ Massa unitária } \\
\hline & & s.s.s. & seca & \multicolumn{2}{|c|}{ aparente } & \multicolumn{3}{|c|}{ solta } & \multicolumn{4}{|c|}{$\begin{array}{c}4 \% \\
\text { umidade }\end{array}$} \\
\hline & & $\left(\mathrm{g} / \mathrm{cm}^{3}\right)$ & $\left(\mathrm{g} / \mathrm{cm}^{3}\right)$ & \multicolumn{2}{|c|}{$\left(\mathrm{g} / \mathrm{cm}^{3}\right)$} & \multicolumn{3}{|c|}{$\left(\mathrm{g} / \mathrm{cm}^{3}\right)$} & \multicolumn{4}{|c|}{$\left(\mathrm{g} / \mathrm{cm}^{3}\right)$} \\
\hline 4,75 & 2,66 & 2,630 & 2,646 & \multicolumn{2}{|c|}{2,622} & \multicolumn{3}{|c|}{1,549} & \multicolumn{4}{|c|}{1,179} \\
\hline \multicolumn{3}{|c|}{ Absorção } & \multicolumn{3}{|c|}{ Pulverulento } & \multirow{2}{*}{\multicolumn{7}{|c|}{ Matéria orgânica }} \\
\hline \multicolumn{3}{|c|}{$(\%)$} & \multicolumn{3}{|c|}{$(\%)$} & & & & & & & \\
\hline & 0,30 & & & 0,78 & & \multicolumn{7}{|c|}{ +clara } \\
\hline
\end{tabular}

Tabela 3 - Resultados dos ensaios físicos para o agregado miúdo

\begin{tabular}{|c|c|c|c|c|c|c|c|c|c|c|c|c|}
\hline Peneiras & \multicolumn{12}{|c|}{$\%$ Retida acumulada } \\
\hline$(\mathrm{mm})$ & 0,150 & 0,300 & 0,600 & 1,180 & 2,36 & 4,75 & 6,30 & 9,50 & 12,5 & 19,0 & 25,0 & 31,5 \\
\hline Brita & 100,0 & 100,0 & 100,0 & 100,0 & 100,0 & 99,7 & 99,1 & 88,3 & 70,4 & 3,5 & 0,0 & 0,0 \\
\hline \multirow{3}{*}{$\begin{array}{c}\Phi \\
\text { Máx. } \\
(\mathrm{mm})\end{array}$} & \multirow{3}{*}{$\begin{array}{l}\text { Modulo } \\
\text { de } \\
\text { finura }\end{array}$} & \multicolumn{4}{|c|}{ Massa específica } & \multirow{2}{*}{\multicolumn{7}{|c|}{ Massa unitária }} \\
\hline & & s.s.s. & seca & \multicolumn{2}{|c|}{ aparente } & & & & & & & \\
\hline & & $\left(\mathrm{g} / \mathrm{cm}^{3}\right)$ & $\begin{array}{c}\left(\mathrm{g} / \mathrm{cm}^{3}\right. \\
)^{3}\end{array}$ & \multicolumn{2}{|c|}{$\left(\mathrm{g} / \mathrm{cm}^{3}\right)$} & \multicolumn{7}{|c|}{$\left(\mathrm{g} / \mathrm{cm}^{3}\right)$} \\
\hline 19,0 & 6,91 & 2,925 & 2,883 & \multicolumn{2}{|c|}{3,010} & \multicolumn{7}{|c|}{1,590} \\
\hline \multicolumn{6}{|c|}{ Absorção } & \multicolumn{7}{|c|}{ Pulverulento } \\
\hline \multicolumn{6}{|c|}{$(\%)^{3}$} & \multicolumn{7}{|c|}{$(\%)$} \\
\hline \multicolumn{6}{|c|}{1,43} & \multicolumn{7}{|c|}{0,36} \\
\hline
\end{tabular}

Tabela 4 - Resultados dos ensaios físicos para o agregado graúdo 


\begin{tabular}{|c|c|c|c|c|c|c|c|c|c|c|c|c|}
\hline Peneiras & \multicolumn{12}{|c|}{$\%$ Retida acumulada } \\
\hline$(\mathrm{mm})$ & 0,075 & 0,150 & 0,300 & 0,600 & 1,18 & 2,36 & 4,75 & 6,3 & 9,5 & 12,5 & 19 & 25 \\
\hline Borracha & 100,0 & 100,0 & 99,8 & 99,4 & 85,8 & 0,6 & 0,0 & 0,0 & 0,0 & 0,0 & 0,0 & 0,0 \\
\hline $\begin{array}{c}\Phi \\
\text { máx. }\end{array}$ & $\begin{array}{c}\text { Modulo } \\
\text { de }\end{array}$ & \multicolumn{6}{|c|}{ Massa específica } & \multicolumn{5}{|c|}{ Massa unitária } \\
\hline$(\mathrm{mm})$ & Finura & \multicolumn{6}{|c|}{$\left(\mathrm{g} / \mathrm{cm}^{3}\right)$} & \multicolumn{5}{|c|}{$\left(\mathrm{g} / \mathrm{cm}^{3}\right)$} \\
\hline 2,36 & 3,86 & \multicolumn{6}{|c|}{1,150} & \multicolumn{5}{|c|}{0,320} \\
\hline
\end{tabular}

Tabela 5 - Resultados dos ensaios físicos para a borracha de pneu

\begin{tabular}{c|c|c|c|c}
\hline Material & $\begin{array}{c}\text { Controle } \\
(\mathbf{5 \%} \text { SA) }\end{array}$ & $\mathbf{5 \%} \mathbf{C C A}$ & SA Borracha & $\begin{array}{c}\text { CCA } \\
\text { Borracha }\end{array}$ \\
\hline Abatimento (cm) & 21,3 & 20,0 & 21,0 & 19,8 \\
\hline
\end{tabular}

Tabela 6 - Resultados do ensaio de abatimento do tronco de cone

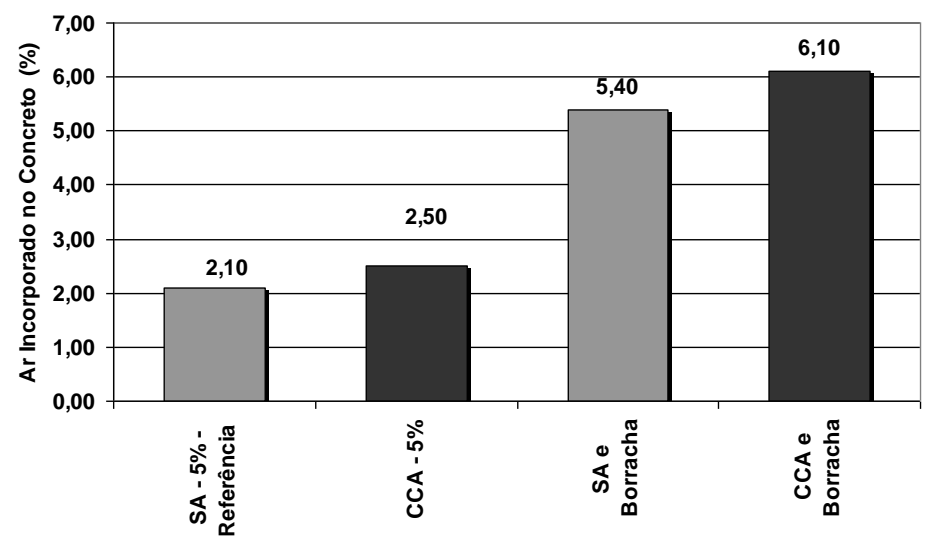

Figura 4 - Incorporação de ar no concreto

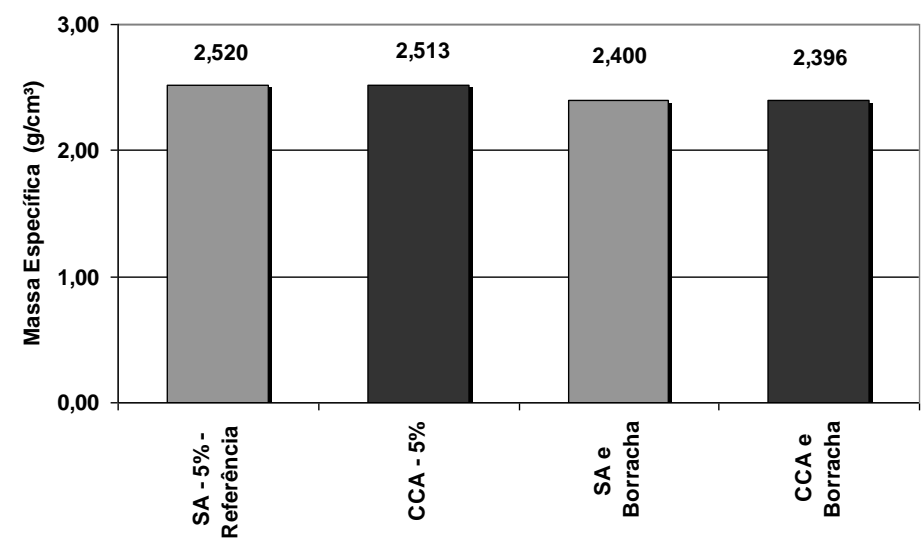

Figura 5 - Massa específica do concreto fresco

O formato alongado do resíduo da borracha de pneu e sua superfície áspera contribuíram para o aprisionamento de bolhas de ar. Consequentemente, os traços com essa adição aumentaram a porcentagem de ar incorporado no concreto, como mostra a Figura 4. O ensaio seguiu as recomendações da NBR NM 47:2002.

Como a CCA e a borracha de pneu possuem massa específica inferior a do cimento e da areia respectivamente, a realização de traços dosados com essas adições apresentaram queda na massa 
específica em relação ao traço controle com sílica ativa, como mostra a Figura 5.

Com a finalização dos ensaios de abatimento do tronco de cone e incorporação de ar no concreto, moldaram-se os CPs para os demais ensaios, seguindo as recomendações da NBR 5738 (ABNT, 2008).

O ensaio de resistência à compressão foi feito para acompanhar o desempenho dos traços realizados, classificando-os como concretos de alto desempenho, e também para evidenciar as possíveis influências das adições dos resíduos, seguindo os procedimentos da NBR 5739 (ABNT, 2007).
A seguir, a Figura 6 contém os resultados das resistências à compressão para cada um dos traços nas respectivas idades de ruptura.

A adição da CCA apresentou resultados satisfatórios para a absorção de água por imersão, entretanto a sílica ativa mostrou-se mais eficiente na diminuição da absorção de água em relação aos traços dosados com CCA.

A adição de borracha também promoveu queda na absorção, quando comparada com os outros traços sem essa adição, e não indicou variação grande da absorção entre 7 e 28 dias.

A Figura 7, a seguir, mostra os resultados do ensaio de absorção de água por imersão.
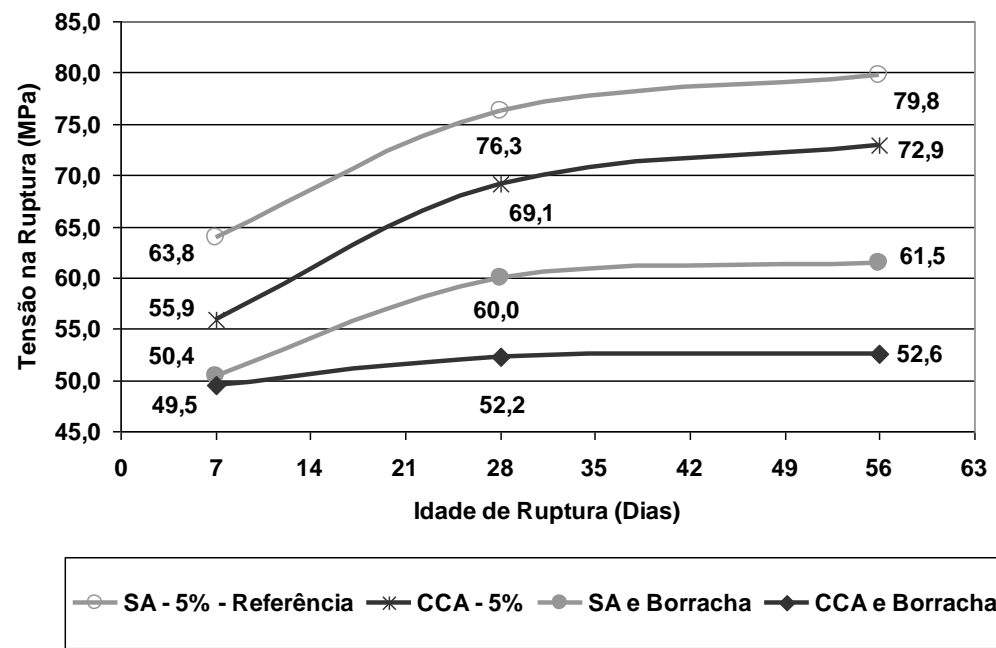

Figura 6 - Resistência à compressão dos traços estudados

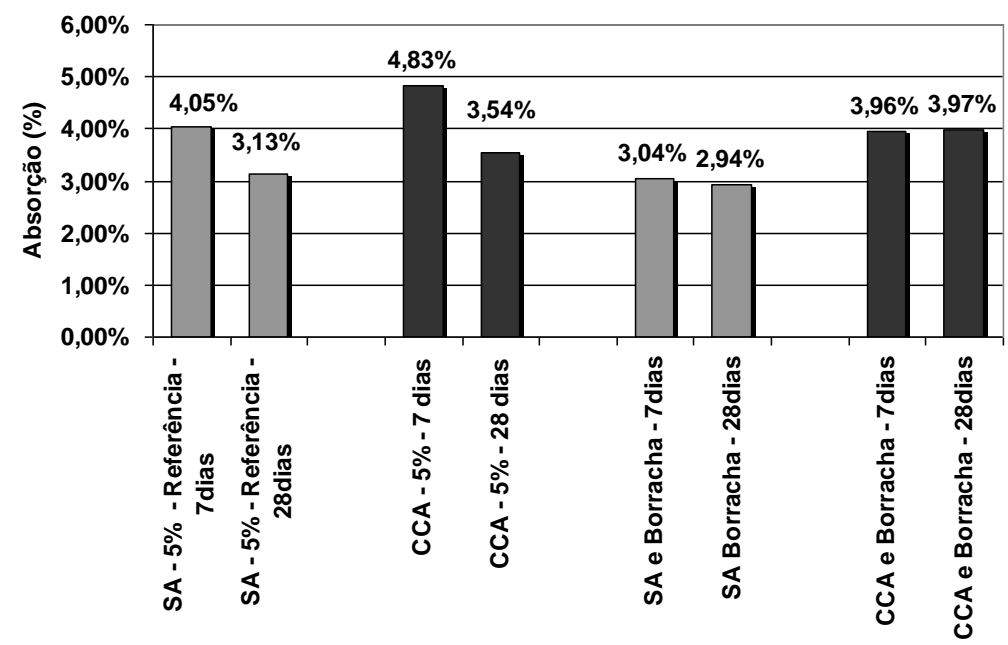

Figura 7 - Absorção de água por imersão no concreto 
A Figura 8 mostra os resultados do ensaio de absorção por capilaridade no concreto. Pode-se observar que houve aumento na absorção por capilaridade aos 28 dias apenas para o traço dosado com CCA e borracha de pneu juntos.

O ensaio de penetração de água sobre pressão mostrou que as penetrações nos CPs foram consideradas baixas para a caracterização da permeabilidade. Sendo assim, como as medidas foram muito próximas a $5 \mathrm{~mm}$, considerou-se o resultado como impermeável para todos os traços. A Figura 9 mostra as profundidades de penetração de água no concreto.

Para o ensaio de ciclagem artificial água/estufa, a primeira constatação foi que as massas dos CPs mantiveram-se praticamente constantes no decorrer do ensaio.
O quadro de desagregação também foi um dos pontos avaliados pelo ensaio, mas, como o concreto tinha uma resistência muito alta, chegando a valores próximos $80 \mathrm{MPa}$ para os traços sem borracha e valores próximos a $60 \mathrm{MPa}$ para os traços com borracha, a desagregação não foi observada em nenhum traço.

Para aumentar o efeito da mudança de temperatura e de clima, optou-se durante a fase de realização do ensaio por retirar os CPs da estufa, a $105^{\circ} \mathrm{C}$, e imergi-los, na sequência, no tanque com água.

O choque térmico proveniente da mudança brusca de temperatura favoreceu a formação do quadro de fissuração no concreto, e as fissuras, mesmo não tendo grande abertura, ocasionaram a lixiviação de material carbonático do interior do concreto para a superfície.

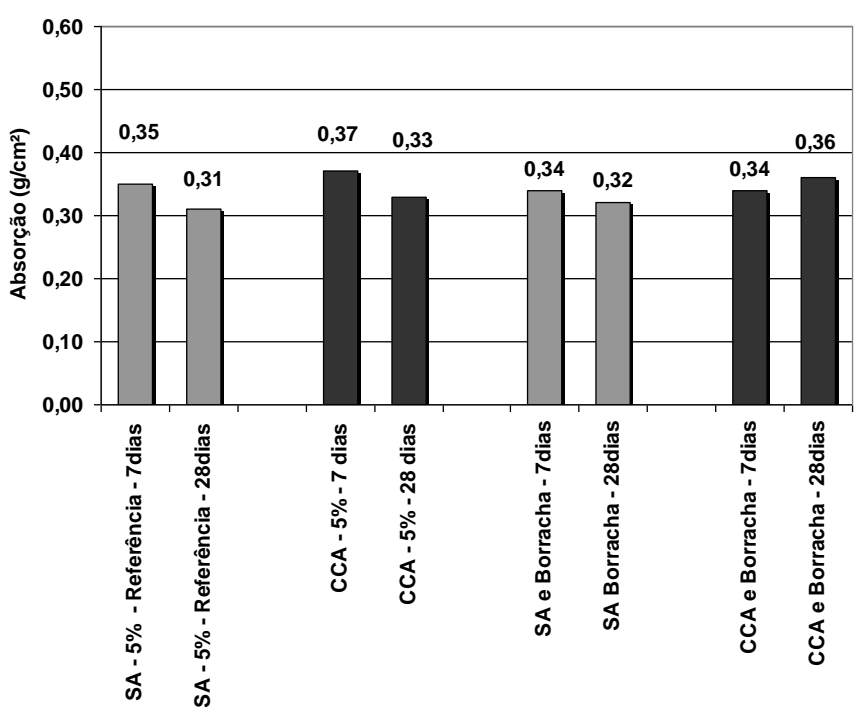

Figura 8 - Absorção de água por capilaridade no concreto

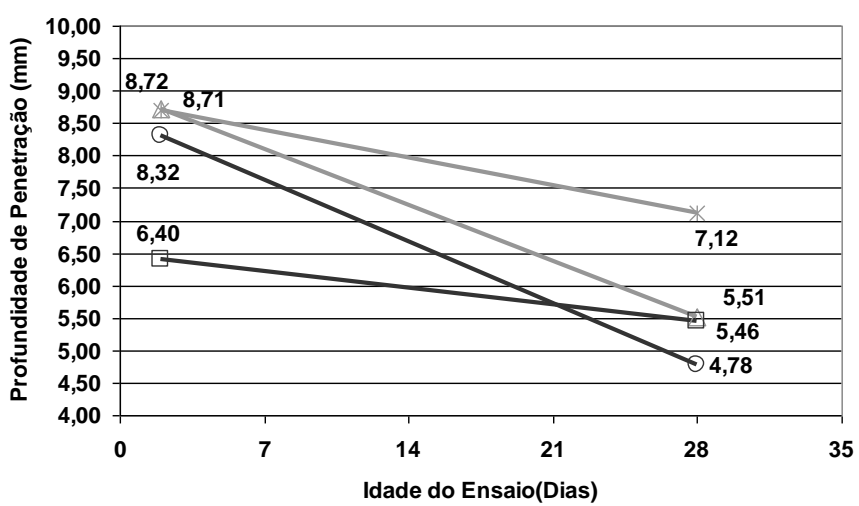

$$
\begin{aligned}
& \triangle \text { SA - Referência - } 5 \% \text { - CCA - } 5 \% \\
& * \text { SA e Borracha } \quad \text { CCA e Borracha }
\end{aligned}
$$

Figura 9 - Penetração de água sob pressão 
A ação prolongada da alta temperatura no concreto também favoreceu a perda de elasticidade das partículas fibrosas de borracha de pneu na camada superficial do concreto.

O comprimento das fissuras longitudinais foi maior nos CPs sem adição de borracha de pneu.
A Figura 10 mostra o resultado da compressão axial no concreto após a realização dos 120 ciclos A lixiviação do $\mathrm{Ca}(\mathrm{OH})_{2}$, retirando o carbonato de cálcio, que é solúvel, do interior do concreto e levando-o para a superfície, foi caracterizada pelo surgimento de eflorescências na superfície do concreto, como se verifica nas Figuras 11 e 12.

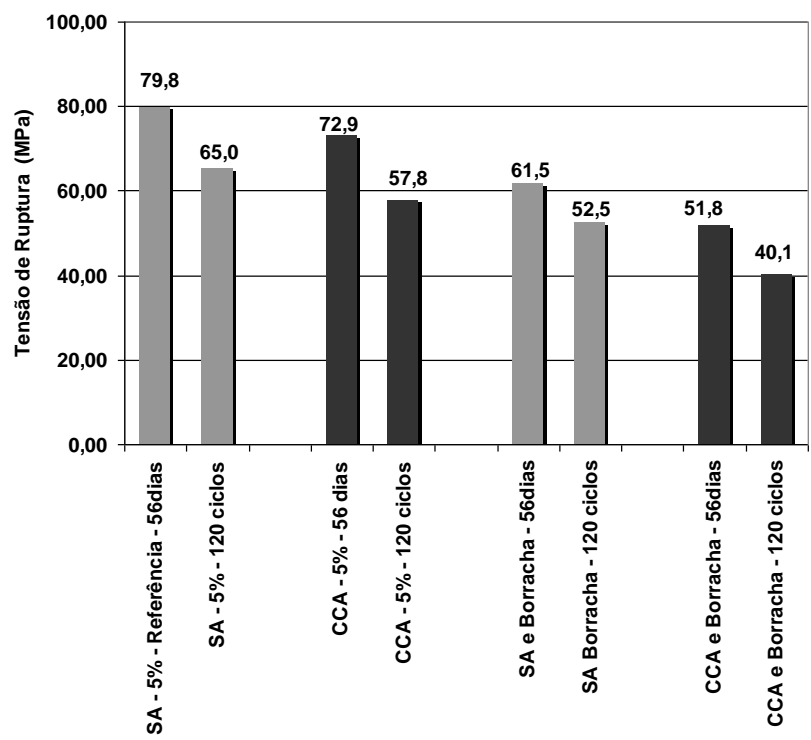

Figura 10 - Comparação da resistência à compressão antes e após o ensaio

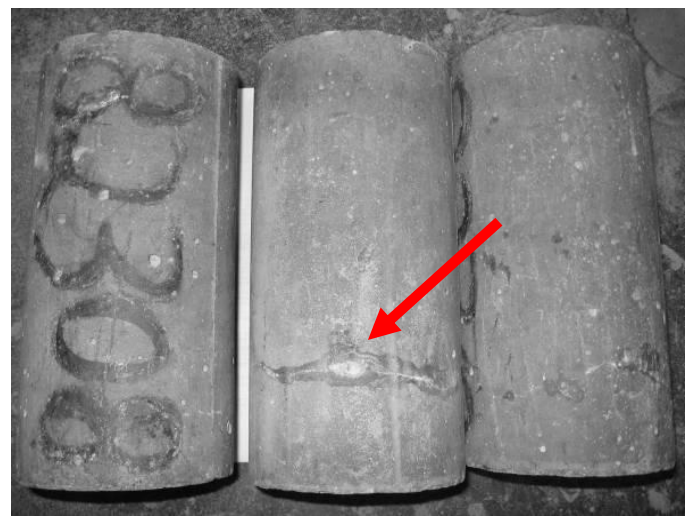

Figura 11 - Aparecimento de eflorescência

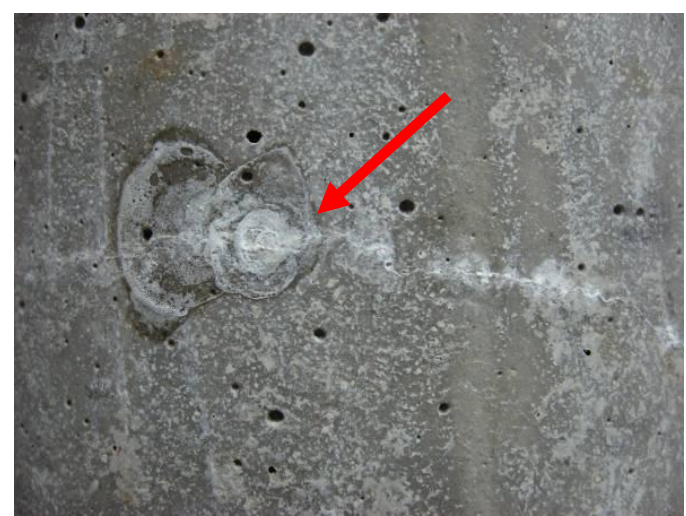

Figura 12 - Detalhe da eflorescência 
No ensaio de ciclagem com ácido lático para verificação da resistência ao ataque químico no concreto, o traço contendo apenas CCA apresentou maior porcentagem de perda de massa. Os dois traços com adição de borracha conseguiram impedir com maior sucesso a entrada de agentes agressores e apresentaram as menores perdas de massa, conforme mostra a Figura 13.

A penetração de cloretos no concreto pode ter sido influenciada por uma modificação em sua microestrutura, gerado caminhos preferenciais nos traços com adição de borracha, de maneira que a água e os íons puderam entrar com maior facilidade, embora a diferença de penetração entre os traços com e sem borracha fosse em torno de 2 mm, como mostra a Figura 14.

O ensaio de abrasão por erosão mostrou que os traços contendo borracha obtiveram as menores perdas de massa, enquanto os mesmos sem essa adição apresentaram maior perda de massa superficial, conforme mostra a Figura 15.

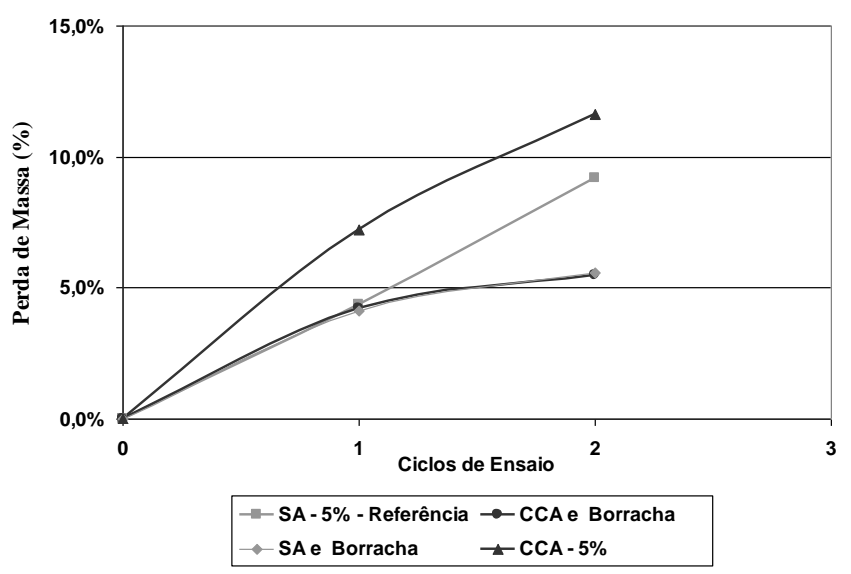

Figura 13 - Resultado da perda de massa após o ataque químico

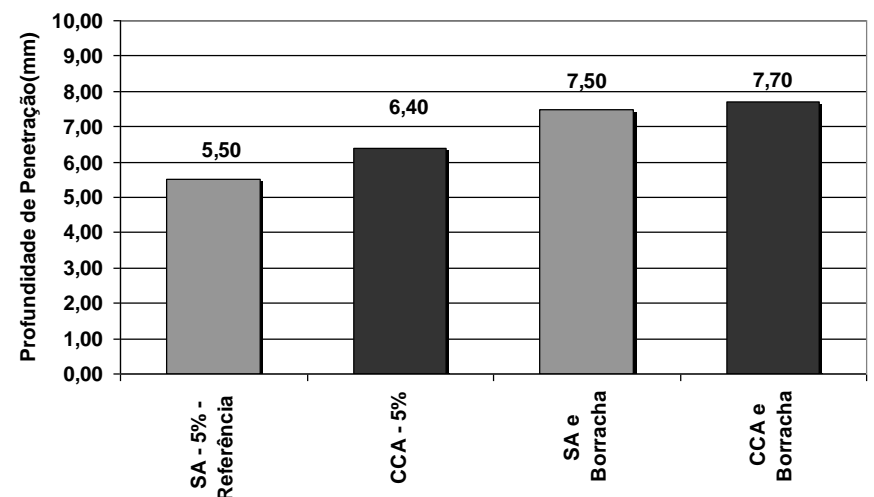

Figura 14 - Profundidade de penetração de cloretos

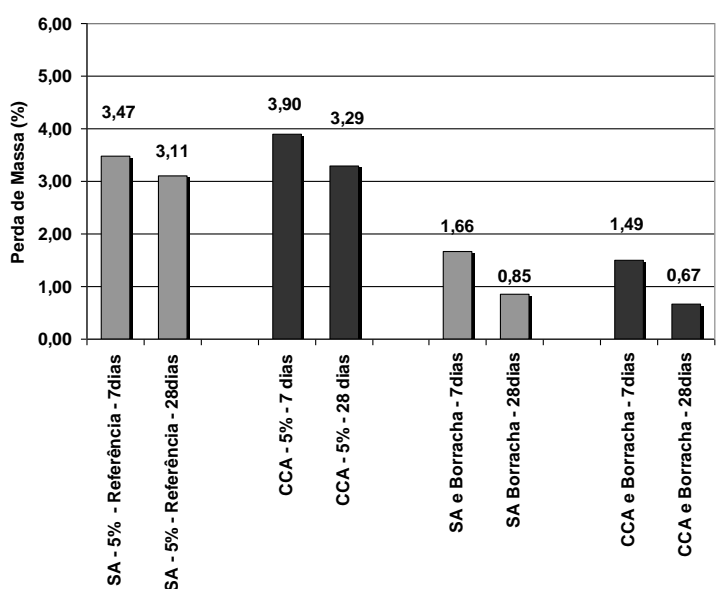

Figura 15 - Perda de massa por abrasão/erosão 


\section{Conclusões}

A queda de resistência à compressão nos traços estudados foi observada tanto para as adições de CCA quanto para a borracha de pneu, sendo a queda de $10 \%$ quando adicionada a CCA, de $20 \%$ para borracha de pneu e de $30 \%$ para as duas no mesmo traço, em relação ao traço referência, com sílica ativa.

A comparação desses resultados com o traçoreferência evidencia ainda a superioridade da sílica ativa na produção do $\mathrm{CAD}$, sabendo-se que a SA comercial possui granulometria bem mais fina que a CCA, o que pode justificar a queda de resistência, uma vez que a composição química de ambas é semelhante e à base de $\mathrm{SiO}_{2}$.

Os resultados do ensaio de absorção de água por imersão mostraram aumento na absorção para os traços com a adição de CCA em substituição à SA. Os traços com SA e borracha tiveram os resultados dentro de uma mesma faixa do intervalo de amostragem, sem poder afirmar a influência dessa adição. A absorção de água por capilaridade não mostrou influência significativa para as adições em estudo.

O ensaio de penetração de água sob pressão mostrou resultados muito dispersos, tendo como melhor forma de avaliação desse ensaio a análise individual dos traços em relação a sua idade de ensaio. Todos os traços apresentaram resultados inferiores a $10 \mathrm{~mm}$ de penetração de água sob pressão.

O quadro de fissuração no ensaio de ciclagem mostrou que a borracha de pneu teve a ação de impedir a continuidade das fissuras e também auxiliou a contenção da lixiviação de material carbonático, o que foi mais evidenciado nos traços sem adição de borracha. Já a queda na resistência à compressão neste ensaio apresentou valores semelhantes para SA e CCA, $14 \mathrm{MPa}$ e $15 \mathrm{MPa}$ respectivamente, e a borracha de pneu obteve as menores quedas, $11 \mathrm{MPa}$ para ambos os traços com borracha e SA e com borracha e CCA, sendo mais resistente a essa solicitação.

Em relação ao ensaio de ataque químico por ácido lático, os traços contendo borracha de pneu mostraram que essa adição proporciona menor perda de massa nos CPs. Já o traço contendo apenas CCA apresentou perda de massa superior quando comparado à sílica ativa.

Em relação à penetração de cloretos, uma diferença entre a microestrutura dos concretos pode ter apresentado caminhos preferenciais nos traços com borracha, de maneira que a água tenha entrado com mais facilidade, mas em pequena quantidade. Sendo assim, ocorreu maior entrada dos íons cloreto nos traços contendo a adição de borracha, embora a diferença de penetração entre os traços com e sem borracha fosse próximo de 2 $\mathrm{mm}$.

Em geral, a durabilidade não foi comprometida com adição dos resíduos propostos no trabalho além disso, a borracha de pneu mostrou, mesmo com massa específica inferior a dos traços sem essa adição, valores similares para absorção de água e eficácia no combate à ação de agentes químicos e aos ciclos de água/estufa.

Para os traços com CCA, vale ressaltar que, mesmo com maior diâmetro de suas partículas, conseguiram resultados similares aos da sílica ativa, lembrando que o resíduo foi processado sem controle de temperatura.

\section{Referências}

AITCIN, P. C. Concreto de Alto Desempenho. São Paulo: PINI, 2000.

AKASAKI, J. L. et al. Avaliação do Resíduo Agroindustrial como Alternativa Ecologicamente Correta para Construção Ccivil. In: JORNADAS SULDAMERICANAS DE INGENIERIA ESTRUCTURAL, 33., 2008, Santiago. Jornada... Chile, 2008. 1 CD-ROM.

\section{AMBIENTE BRASIL. Reciclagem de Pneu. Disponível em: \\ <http://www.ambientebrasil.com.br>. Acesso em: 26 mar. 2007.}

ANDRADE, Jairo José de Oliveira et al. Avaliação das Características do Concreto Quando Submetido à Degradação de Origem Química. In: CONGRESSO BRASILEIRO DE CONCRETO, 45., 2003, Vitória. Anais... São Paulo: Ibracon, 2003. 1 CD-ROM.

ARROZ BRASILEIRO. Brasileiro. Disponível em: <http://www.arroz.agr.br>. Acesso em: 25 ago. 2008.

\section{ASSOCIAÇÃO BRASILEIRA DE NORMAS} TÉCNICAS. NBR 10787: concreto endurecido: determinação da penetração de água sob pressão. Rio de Janeiro: ABNT, 1994. 6 p.

\section{ASSOCIAÇÃO BRASILEIRA DE NORMAS} TÉCNICAS. NBR 12696: agregados: verificação do comportamento mediante ciclagem artificial água-estufa. Rio de Janeiro: ABNT, 1992. 3p. 
ASSOCIAÇÃO BRASILEIRA DE NORMAS TÉCNICAS. NBR 5738: concreto: procedimento para moldagem e cura de corpos-de-prova. Rio de Janeiro: ABNT, 2008. 6 p.

\section{ASSOCIAÇÃO BRASILEIRA DE NORMAS} TÉCNICAS. NBR 5739: concreto: ensaio de compressão de corpos-de-prova cilíndricos. Rio de Janeiro: ABNT, 2007. 9 p.

\section{ASSOCIAÇÃO BRASILEIRA DE NORMAS}

TÉCNICAS. NBR 9778: argamassa e concreto endurecidos: determinação da absorção de água por imersão, índice de vazios e massa específica. Rio de Janeiro: ABNT, 2005. 4 p.

\section{ASSOCIAÇÃO BRASILEIRA DE NORMAS} TÉCNICAS. NBR 9779: argamassa e concreto endurecidos: determinação da absorção de água por capilaridade. Rio de Janeiro: ABNT, 1995. 2 p.

\section{ASSOCIAÇÃO BRASILEIRA DE NORMAS} TÉCNICAS. NBR 9833: concreto fresco: determinação da massa específica, do rendimento e do teor de ar pelo método gravimétrico. Rio de Janeiro: ABNT, 2008. 7 p.

\section{ASSOCIAÇÃO BRASILEIRA DE NORMAS}

TÉCNICAS. NBRNM 47: concreto: determinação do teor de ar em concreto fresco - método pressométrico. Rio de Janeiro, 2002. 23 p.

\section{ASSOCIAÇÃO BRASILEIRA DE NORMAS} TÉCNICAS. NBRNM 67: concreto: determinação da consistência pelo abatimento o tronco de cone. Rio de Janeiro: ABNT, 1998. 8 p.

BARBOSA, M. B. Utilização de Resíduos de Cinza de Casca de Arroz e Borracha de Pneus em Concreto de Alto Desempenho. 2006. $161 \mathrm{f}$. Dissertação (Mestrado em Engenharia Civil) Escola de Engenharia, Universidade Estadual Paulista, Ilha Solteira, 2006.

CHAN, W. W. J.; WU, C. M. L. Durability of Concrete with High Cement Replacement. Cement and Concrete Research, Elmsford, v. 30, n. 6, p. $865-879,2000$

DAL MOLIN, D. et al. Estudo de Concretos com Adição de Sílica Ativa (Microssílica) Frente ao Ataque de Agentes Agressivos para Emprego em Pisos Especiais. In: INTERNATIONAL CONGRESS ON HIGH-PERFORMANCE CONCRETE AND PERFORMANCE AND QUALITY OF CONCRETE STRUCTURES, 1., 1996, Florianópolis. Proceedings... Florianópolis: UFSC, 1996. p. 590-598.
FERREIRA, R. M. Optimização da Vida Útil das Estruturas de Betão Armado. In: JORNADAS PORTUGUESAS DE ENGENHARIA DE ESTRUTURAS, 4., 2006, Lisboa. Jornada... Portugal, 2006. Disponível em: <https://repositorium.sdum.uminho.pt $>$. Acesso em: 2 jul. 2008.

HERNÁNDEZ, F. O.; BARLUENGA, G. Fire Performance of Recycled Rubber-Filled HighStrength Concrete. Cement and Concrete Research, Elmsford, v. 34, n. 1, p. 109-117., 2003.

ISAIA, G. C. Questões de Ensino e Pesquisa na Durabilidade das Estruturas do Concreto. e-Mat, Santa Maria, v. 2, n. 2, p. 92-104, 2005.

MEDEIROS, B. L. Estruturas Subterrâneas de Concreto: levantamento de manifestações patológicas na região metropolitana de Curitiba e análise de sistemas de reparo. 2005. $143 \mathrm{f}$. Dissertação (Mestrado em Engenharia Civil) Setor de Tecnologia, Universidade Federal do Paraná, Curitiba, 2005.

MEHTA, P. Kumar; MONTEIRO, Paulo J. M. Concreto: estrutura, propriedades e materiais. Tradução de Paulo Helene. São Paulo: PINI, 1994. $580 \mathrm{p}$.

PRUDÊNCIO JUNIOR, L. R; SANTOS, S.; DAFICO, D. A. Utilização de Resíduos na Construção Habitacional: cinza de casca de arroz. Santa Catarina: Finep, 2003. (Coletânea HABITARE)

SANTOS, G. R. S. et al. Avaliação da Intensidade de Deterioração de uma Estrutura de Concreto Armado Localizada em Ambiente Marinho e Exposta à Ação de Solução Ácida: estudo de caso. In: CONGRESSO BRASILEIRO DO CONCRETO, 48., 2006, Rio de Janeiro. Anais... São Paulo: Ibracon, 2006. 1 CD ROM.

SENSALE, G. R.; DAL MOLIN, D. C. C. Estudo Comparativo entre as Propriedades Mecânicas e Durabilidade de Concretos de Alta Resistência e Convencionais com Cinza de Casca de Arroz. In: CONGRESSO BRASILEIRO DO CONCRETO, 43., 2001, Foz do Iguaçu. Anais... São Paulo: Ibracon, 2001. 1 CD ROM.

SILVA, F. G. Estudos de Concretos de Alto Desempenho Frente à Ação de Cloretos. 2006. 236 f. Tese (Doutorado em Engenharia Civil) Escola de Engenharia de São Carlos, Universidade de São Paulo, São Carlos, 2006. 
SILVA, F. G.; LIBÓRIO, J. Estudo da Penetração de Íons Cloreto em Concretos de Alto Desempenho. In: CONGRESSO BRASILEIRO DO CONCRETO, 46., 2004, Florianópolis. Anais... São Paulo: Ibracon, 2004. 1 CD ROM.

VIEIRA, F. P. et al. Estudos de Durabilidade em Concretos e Argamassas com Adição de

Microssílica. Disponível em:

<www.allquimica.com.br/arquivos/websites/artigo s/WS_Durabilidade200612261066>. Acesso em: 19 ago. 2008.

ZHANG, Min-Hong; LASTRA, R.; MALHOTRA, V. M. Rice-Husk Ash Paste and Concrete: some aspects of hydration and the microstructure of the interfacial zone between the aggregate and paste.

Cement and Concrete Research, Elmsford, v. 26, n. 6, p. 963-977, 1996.

\section{Agradecimentos}

Ao CNPq - Conselho Nacional de Desenvolvimento Científico e Tecnológico, pelo auxílio financeiro.

Ao Laboratório CESP de Engenharia Civil de Ilha Solteira, SP, pelo auxílio na execução dos ensaios e discussão destes.

Ao Laboratório de Engenharia Civil da UNESP, pelo auxílio na execução dos ensaios e discussão destes.

À Holcim Brasil, pela doação do cimento utilizado na pesquisa.

À Regigante - Recuperação de Pneus Gigantes Ltda., pela doação do resíduo de borracha de pneu. 